\title{
Influence of milk on phenolic composition and antioxidant power of black tea
}

\author{
KM Meselhy, ${ }^{1 *}$, Ghada A Abdel-latif ${ }^{2}$, Amany A sleem ${ }^{3}$, Walaa Ayman ${ }^{4}$, Maram.K.Imam ${ }^{4}$, Kholoud A Kassab4, \\ Sherouk Eissa ${ }^{4}$
}

KM Meselhy',*, Ghada

A Abdel-latif ${ }^{2}$, Amany A

sleem ${ }^{3}$, Walaa Ayman ${ }^{4}$,

Maram.K.Imam ${ }^{4}$, Kholoud A

Kassab $^{4}$, Sherouk Eissa ${ }^{4}$

'Pharmacognosy Department, Faculty of Pharmacy, Cairo University, EGYPT.

2Pharmacology \& Toxicology Department, Faculty of Pharmacy, Misr International University, EGYPT.

${ }^{3}$ Pharmacology Department, National

Research Center, Giza, EGYPT.

${ }^{4}$ Fresh graduates, research center, Faculty

of Pharmacy, Misr International University, EGYPT.

\section{Correspondence}

Khaled Meselhy Ibrahim, PhD

Department of Pharmacognosy, Faculty of Pharmacy, Cairo University, Cairo 11562, EGYPT.

E-mail: kmeselhy@hotmail.com

History

- Submission Date: 31-07-2019;

- Review completed: 21-08-2019;

- Accepted Date: 21-08-2019.

DOI : 10.5530/pj.2019.11.196

Article Available online http://www.phcogj.com/v11/i6

\section{Copyright}

(c) 2019 Phcogj.Com. This is an openaccess article distributed under the terms of the Creative Commons Attribution 4.0 International license.

\begin{abstract}
Introduction: Tea leaves are rich in several polyphenolics and flavonoidal compounds that could potentially have health-promoting properties. The objective of the present study was to analyze the antioxidant capacity of black tea and to study the effect of addition of fresh milk and packed milk on the phenolics concentrations and antioxidant efficacy. Methods: The black tea infusion (BT), black tea infusion with fresh milk (BTFM) \& black tea infusion with packed milk (BTPM) samples were comparatively analyzed for total phenolics, flavonoids and HPLC profiling of major phenolic content. All samples were investigated for their total antioxidant capacity and glutathione level in different organs (brain, liver, kidney and heart). Results: The results shown that $\mathrm{BT}$ (black tea infusion) had higher total phenolics and flavonoids followed by BTPM (black tea infusion with packed milk) and then the BTFM (black tea infusion with fresh milk). The analytical HPLC results obtained also indicated that BT contained higher amount of catechins and garlic acid derivatives than BTFM, and BTPM may be due to chelation of free phenolics with some fats and protein in the tested milk samples, which reduces the levels of free phenolics significantly. Concerning antioxidants capacity both tested milk samples reduced antioxidant capacity to more than $50 \%$ in different tested tissues. Conclusion: We conclude that black tea is a valuable source of antioxidants and that the inhibitory effect of milk on the total antioxidant capacity may be related to complex formation of the fat \& protein content of the milk with major phenolics in the black tea.
\end{abstract}

Key words: Black tea, Milk, HPLC. Flavonoids, Phenolics, Antioxidant, Glutathione.

\section{INTRODUCTION}

Tea, Camellia sinensisis one of the most drinks which consumed daily routine by most people after water. It cultivates best in tropical and subtropical areas with different levels of total phenol mostly flavonoid compounds. ${ }^{1-3}$ Antioxidant capacity of tea polyphenolics particularly widely studied in literatures. The flavonoids and tannins have potent antioxidant activity and therefore have been suggested for health benefits such as cancer and coronary heart disease risk reduction and also responsible for the flavor and color of tea. In fermented (Black Tea) type, fermentation stage was occurred before drying and steaming and thus, oxidization of catechin was carried out by active polyphenol oxidase in controlled temperatures and humidity. Result in, polymerisations of catechins were occurred and theaflavins and the arubigins instead of catechin were induced. ${ }^{4-6}$ According to some studies phenolic compounds in tea reduce the human cardiovascular diseases and cancer mortality. ${ }^{6}$ In a some countries such as Egypt, Iran and India in some area, tea is usually consumed with milk. According to some in vitro study, milk proteins interact with tea polyphenols and reduce total antioxidant activity. Currently, consuming tea with milk significantly changes the biological activities of tea. ${ }^{7,8}$ The present study aimed to estimate effect of milk addition on the phenolic components and antioxidant properties of one tea brand.

\section{MATERIALS AND METHODS}

\section{Plant material}

The tea leave sample and milk were purchased from a supermarket in the Cairo. The black tea sample (4 g) was infused in $100 \mathrm{ml}$ of boiling water in a flask for $30 \mathrm{~min}$. for preparation of mixture milk with tea, $50 \mathrm{ml}$ of tea mixed with $50 \mathrm{ml}$ of pre warmed fresh cow milk or $50 \mathrm{ml}$ of packed milk. After extraction for $30 \mathrm{~min}$ all samples were decanted and dried by freeze drying processes for 48 hours. The lyophilized infusion were stored at the temperature of $4^{\circ} \mathrm{C}$ for further analysis. Each of the extraction were done in a triplicate terms $(n=3)$.

Determination of total phenolic compounds

Total phenol content (TPC) was determined according to the Folin-Ciocaltue assay method as reported in ${ }^{9}$ Briefly, $300 \mu \mathrm{L}$ of the sample, in triplicate terms, were introduced into the test tubes, followed by $1.5 \mathrm{ml}$ of Folin-Ciocaltue reagent (diluted up to tenfold with distilled water) and $1.2 \mathrm{ml}$ of sodium carbonate $(7.5 \%, \mathrm{w} / \mathrm{v})$. The tubes were mixed and placed in a dark room for 30 minutes at room temperature. The absorbance was measured at $765 \mathrm{~nm}$ using UV-visible spectrophotometer (Shimadzu UV160A PC Shimadzu Corporation, Kyoto, Japan), and subsequently Gallic acid was used for constructing the standard curve. The TPC was expressed as mg

Cite this article: Meselhy KM, Abdel-latif GA, Sleem AA, Ayman W, Imam MK, Kassab KA, et al. Influence of milk on phenolic composition and antioxidant power of black tea. Pharmacog J. 2019;11(6):1262-8. 
gallic acid equivalent (GAE), per $100 \mathrm{~g}$ wet weight material. Gallic acid standard were prepared by diluting $100 \mathrm{mg}$ of pure Gallic acid in one liter of distilled water. A series of standard Gallic acid were prepared at $20,40,60,80$ and $100 \mathrm{mg}$ of pure Gallic acid concentration as the reference curve.

\section{Determination of total flavonoid content}

Total flavonoid content (TFC) was determined according to the method proposed in $^{10}$ by using the aluminium trichloride. Briefly, $500 \mu \mathrm{l}$ of the extract solution was added to a test tube with $2.5 \mathrm{ml}$ of distilled water, subsequently, about $150 \mu \mathrm{l}$ of sodium nitrite solution $(5 \% \mathrm{w} / \mathrm{v})$ was added to the mixture and kept for 5 minutes, followed by adding $300 \mu \mathrm{l}$ of aluminium chloride. At the 6 th minute, $1 \mathrm{ml}$ of $1 \mathrm{M}$ sodium hydroxide $(\mathrm{NaOH})$ was added to the solution. The mixture was further diluted with $550 \mu$ of distilled water and shaken vigorously. The absorbance of the mixture was measured at $510 \mathrm{~nm}$ using UV-visible spectrophotometer Shimadzu UV-160A PC, Shimadzu Corporation, Kyoto, Japan) and the TPC was expressed as mg quercetin (QE) per100 g sample.

\section{Determination of total phenolic and flavonoid content by Micro plate reader analysis}

Determination of total phenolics by microtiter plate folin-ciocalteu method for the assessment of polyphenols as described by Attard. ${ }^{11}$ Total flavonoids was quantified by High-throughput micro plate assays for screening flavonoid content as described by Herald. ${ }^{12}$ Microplate reader Fluo Star Omega were used in both cases. Gallic acid was used as standards for determination of total phenolics. Gallic acid stock solution of $1 \mathrm{mg} / \mathrm{ml}$ in methanol was prepared, and 7 serial dilutions were prepared in the concentrations of $500,250,125,62.5,31.2,15.6$, and $7.8 \mu \mathrm{g} / \mathrm{ml}$. Rutin was used as standards for determination of total flavonoids. Rutin stock solution of $1 \mathrm{mg} / \mathrm{ml}$ in methanol was prepared, and 6 standards were prepared in the concentrations of 1000,500,250, 150,100 , and $50 \mu \mathrm{g} / \mathrm{ml}$. Solutions of tested samples of black tea labelled "BT" and black tea with milk (1:1) labelled "BTM" were prepared in concentration of $0.5 \mathrm{mg} / \mathrm{ml}$ in water .Each of the 7 gallic acid standards and 2 tested samples were pipetted in the plate wells in 6 replicates and measurement was performed at $630 \mathrm{~nm}$ Each of the 6 Rutin standards and 2 tested samples were pipetted in the plate wells in 6 replicates and measurement was performed at $510 \mathrm{~nm}$.

\section{HPLC analysis}

Sample Preparation: $0.04 \mathrm{~g}$ of lyophilized black tea (BT) \& back tea milk (BTM) samples were dissolved in $1 \mathrm{ml} \mathrm{70 \%} \mathrm{methanol} \mathrm{and} \mathrm{kept}$ in $70^{\circ} \mathrm{C}$ water bath for 30 minutes. The extracts were cooled to room temperature and diluted to $2 \mathrm{ml}$. Before injection, the tea extracts were filtered using $0.2 \mu \mathrm{m}$ filter and further diluted 200 times using mobile phase A. The wines were filtered using $0.2 \mu \mathrm{m}$ filter before injection. 10 $\mu \mathrm{l}$ injections were used for the tea extracts samples.

\section{HPLC conditions}

HPLC: Prominence (Shimadzu, Duisburg, Germany)Column: 4.6mm x 250mm Phenomenex phenyl hexyl Luna column Mobile phase A: 5\% acetonitrile, $1 \%$ acetic acid in water Mobile phase B: $95 \%$ acetonitrile, $1 \%$ acetic acid in water Flow Rate: $1 \mathrm{ml} / \mathrm{min}$ Gradient: 0-5 min 5\% B, $5.50 \mathrm{~min}$ increase to $13 \% \mathrm{~B}, 9 \mathrm{~min}$ increase to $15 \% \mathrm{~B}$, kept to $44 \mathrm{~min}, 45$ min increase to $95 \% \mathrm{~B}$, then re-flushing to $5 \% \mathrm{~B}$.

\section{HPLC standards}

A mixture of caffeine, gallic acid and 8 catechins (epigallocatechin (EGC), epicatechin ${ }^{5}$, epigallocatechin gallate (EGCG), epicatechin gallate (ECG), gallocatechin (GC), catechin $(\mathrm{C})$, gallocatechin gallate
(GCG), catechin gallate (CG) were used for method development and generating calibration curves.

\section{Antioxidant activity}

\section{Animals}

Adult male albino rats, Sprange Dawely strain weighing between 140 and $150 \mathrm{~g}$, were obtained from National Research Center Animal House Dokki, Giza. The rats were maintained in an animal house with standard facilities. The animals were housed in clean cages and maintained at $25^{\circ} \mathrm{C}$ under $12 \mathrm{~h}$ light-dark cycle, and they were fed with standard feed from (vitamin mixture $1 \%$, mineral mixture $4 \%$, corn oil $10 \%$, Sucrose $20 \%$, cellulose $0.2 \%$, casein $95 \%$ pure $10.5 \%$ and starch $54.3 \%$.

All the pharmacological experiments protocols were conducted according to the ethical norms approved by the National Research Center and followed the recommendations of NRC of Health Guide for care and use of laboratory animals

\section{Experimental design}

The experimental animals were divided into five groups, each comprising of six animals as detailed in the following.

Group 1: control rats received $1 \mathrm{ml}$ saline

Group 2: Rats given vitamin E (7.5 mg/kgb.wt/day) in aqueous solution orally for 30 days.

Group 3: Rats given lyophilized black tea extract ( $10 \mathrm{mg} / \mathrm{kg}$ b.wt/day) in aqueous solution orally for 30 days.

Group 4: Rats given lyophilized black tea fresh milk mixture extract $(10 \mathrm{mg} / \mathrm{kg}$ b.wt/day) in aqueous solution orally for 30 days.

Group 5: Rats given lyophilized black tea packed milk mixture extract $(10 \mathrm{mg} / \mathrm{kg} \mathrm{b.wt} /$ day) in aqueous solution orally for 30 days.

At the end of the total experimental period after one month, the animals were fasted overnight, anaesthetized and sacrificed, by cervical dislocation.

\section{Preparation of tissue homogenate}

The Brain, liver, kidney and heart tissues from the control and experimental groups of rats were excised and rinsed with ice-cold saline. The preparation of tissue homogenates was done by a known amount of the tested tissues, homogenized in $0.1 \mathrm{M}$ Tris- $\mathrm{HCl}$ buffer, $\mathrm{pH} 7.4$ at $4^{\circ} \mathrm{C}$, in a Potter-Elvehjem homogenizer with a Teflon pestle at $600 \mathrm{~g}$ for $3 \mathrm{~min}$. The homogenates were centrifuged at $3,000 \mathrm{~g}$ for $10 \mathrm{~min}$ at $4^{\circ} \mathrm{C}$ using Sorvall refrigerated centrifuge. The supernatant was collected as tissue homogenate, and stored at $-80^{\circ} \mathrm{C}$ for the determination of Total antioxidant capacity as described by (Koracevic et al) $)^{13} \&$ Glutathione reductase GSH as described by (Kaya et al). ${ }^{14}$

\section{RESULTS}

Results display means values \pm standard deviation $(\mathrm{n}=3)$. abc Mean with different superscripts in column indicate significantly different $(p<0.05)$ among treatments. ABC Mean with different superscripts in rows indicate significant difference $(p<0.05)$ among samples.

In both quantitative methods (Tables (1 \& 2) \& Figures (1 \& 2)) BT recorded the highest total phenolic and flavonoids concentration. Total phenolic contents of BT infusion $(180 \& 231 \mathrm{mg} / \mathrm{g}$ dry wt $)$ and flavonoids ( $151 \& 123 \mathrm{mg} / \mathrm{g}$ dry wt) was determined. Addition of milk in BTFM \& BTPM samples reduce free phenolics and flavonoids but reduction in flavonoid is minor and non- significant when compared to a significant reduction in total phenolics. Effect of both types of milk nearly the same and no significant differences between the effects of the two tested types of milk when added to BT sample. 
Generally, HPLC results (Table 3 and Figures 3 \& 4) recorded similar phenolics in all tested samples black tea BT and black tea with milk BTM. Caffeine, gallic acid derivatives and some catechins are the main polyphenols in both samples. All detected phenolics in BT were higher valued than BTM except ECG. Addition of milk to black tea significantly reduce concentration of major gallic and catechin derivatives and this results support previouse results of quantitative determination of total phenolics. The analytical HPLC results may be due to chelation process of milk fats \& protein with free phenolics in the tea, which reduces the levels of catechin and gallic acid derivatives significantly.

Result of determination of antioxidant capacity of tested samples (Table 4 and Figure 5) revealed that both types of milk reduced total antioxidant capacity of tested black tea sample and glutathione level in different organs. The total antioxidant capacity of BT ranged from 3.4 to 4.8 in all tested organs while glutathione level ranged from 5.7 to 6.2 and in tea + milk blend (BTFM \& BTPM) total antioxidant capacity were reduced in all organs and ranged from 2.3 to 2.9 while glutathione level ranged from 4.3 to 5.4 Black tea had the highest antioxidant activity while addition of milk reduced this activity to nearly $1 / 2$ the power and both type of mil either fresh or packed exerted the same effect.

\section{DISCUSSION}

Although the antioxidant capacity and glutathione level were relatively high in black tea sample, the antioxidant activity generally decreased significantly $(p<0.05)$ with addition of milk in equal amount to tea and it was significantly lower both antioxidant capacity and glutathione reductase level. The decrease in antioxidant activity with addition of milk reveals an interaction between tea polyphenols and milk proteins and HPLC results in this study confirmed this fact as concentration of free polyphenols were decreased in tea milk sample BTM when compared to BT without milk. These findings are comparable to those obtained by ${ }^{15}$ who showed that the addition of milk to black tea inhibited the pharmacological activity of tea in cardiovascular endothelial functions while tea without milk had positive effects on the same. Catechins \& gallate derivatives correlated positively with antioxidant activity in black tea and some studies investigate the interaction of individual milk proteins with catechins, the casein proteins were found to decrease the polyphenolic levels ${ }^{[15]}$. The lowering of black tea antioxidant potency by mixed milk may therefore be attributed to the interaction and binding of tea catechins by casein proteins. The interaction and

Tables 1 and 2: Quantitative determination of total flavonoids \& phenolics in tested samples by two different methods.

\begin{tabular}{cccc}
\hline & BT & BTFM & BTPM \\
\hline Total phenolics (mg GAE/g dry weight) & $180.33 \pm 4.2^{\mathrm{cC}}$ & $120.32 \pm 5.03^{\mathrm{cC}}$ & $124.66 \pm 2.1^{\mathrm{cA}}$ \\
Total flavonoids (mg CEQ/g dry weight) & $151.12 \pm 3.1^{\mathrm{aA}}$ & $135.45 \pm 3.06^{\mathrm{cb}}$ & $140.25 \pm 4.3^{\mathrm{cC}}$ \\
\hline & $\mathrm{BT}$ & BTFM & BTPM \\
\hline Total phenolics (mg GAE/g dry extract) & $231.2 \pm 5$ & $182.6 \pm 8.3$ & $179.7 \pm 8.3$ \\
Total flavonoids (mg rut/g dry extract) & $123.8 \pm 4.6$ & $115.2 \pm 4.6$ & $114.2 \pm 4.6$ \\
\hline
\end{tabular}

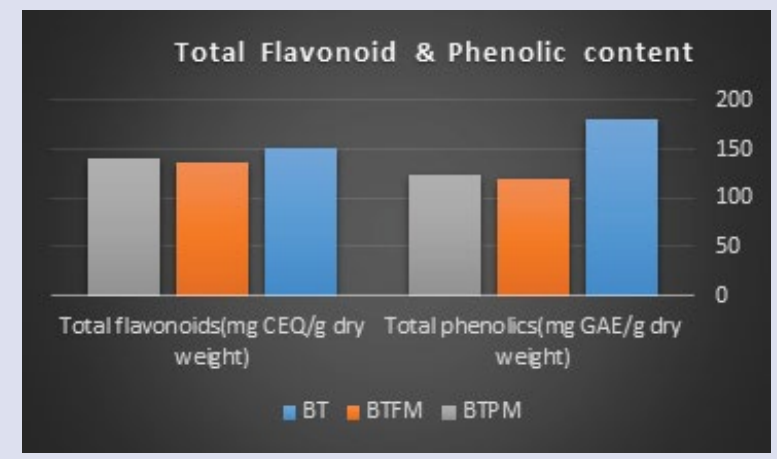

1

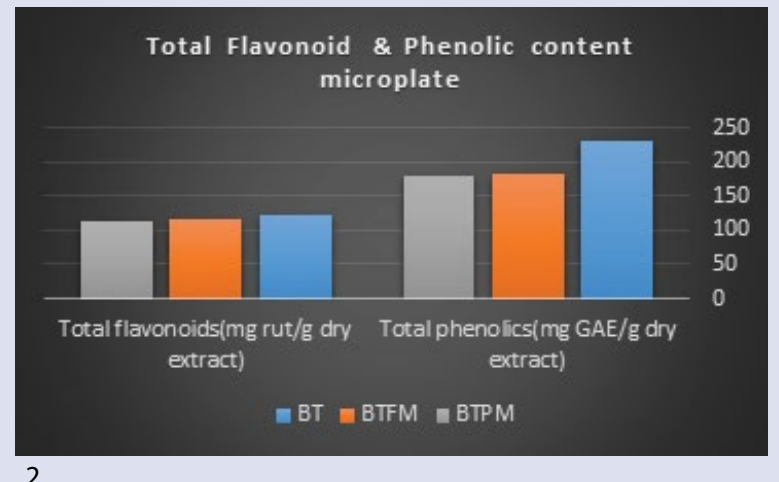

2

Figures 1 and 2: Quantitative determination of total flavonoids \& phenolics tested samples by two different methods.

Table 3: phenolics profile in tested samples by HPLC analysis.

\begin{tabular}{ccc}
\hline & BT & BTM \\
\hline G & 95.82 & 60.31 \\
GC & 46.25 & 29.718 \\
EGC & 20.09 & 12.25 \\
C & 19.25 & 7.382 \\
Caffeine & 804.512 & 672.304 \\
EC & 64.37 & 38.116 \\
EGCG & 36.28 & 29.262 \\
GCG & 45.38 & 36.874 \\
ECG & 26.60 & 61.712 \\
\hline
\end{tabular}



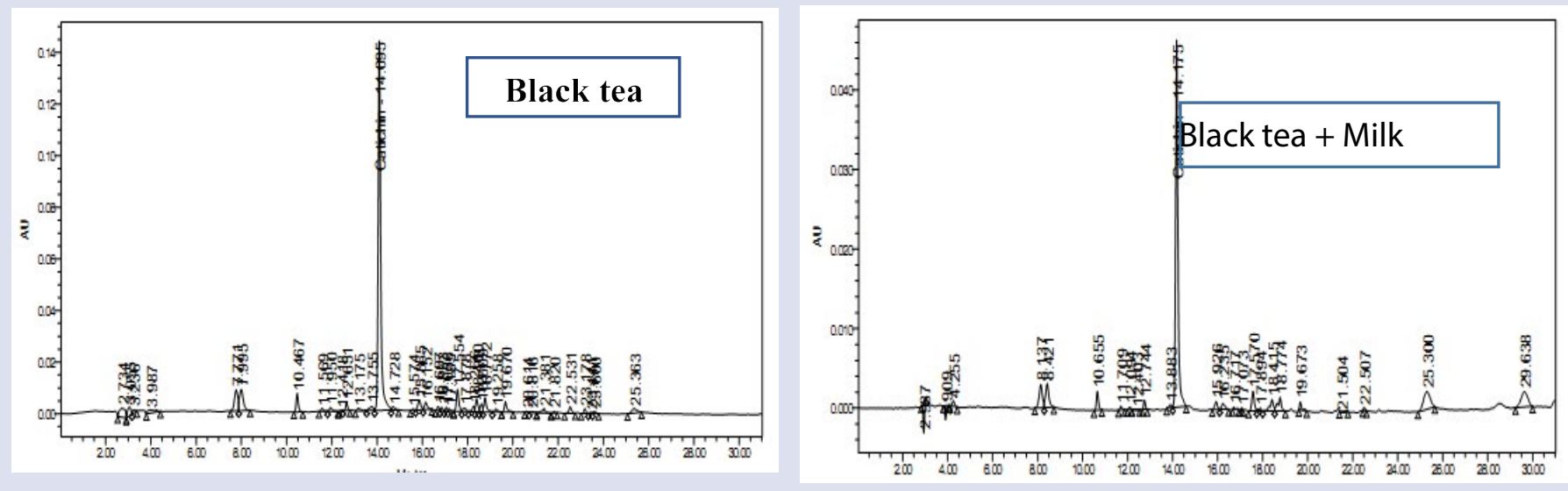

Figure 3: HPLC total ion chromatogram of tested samples phenolics.

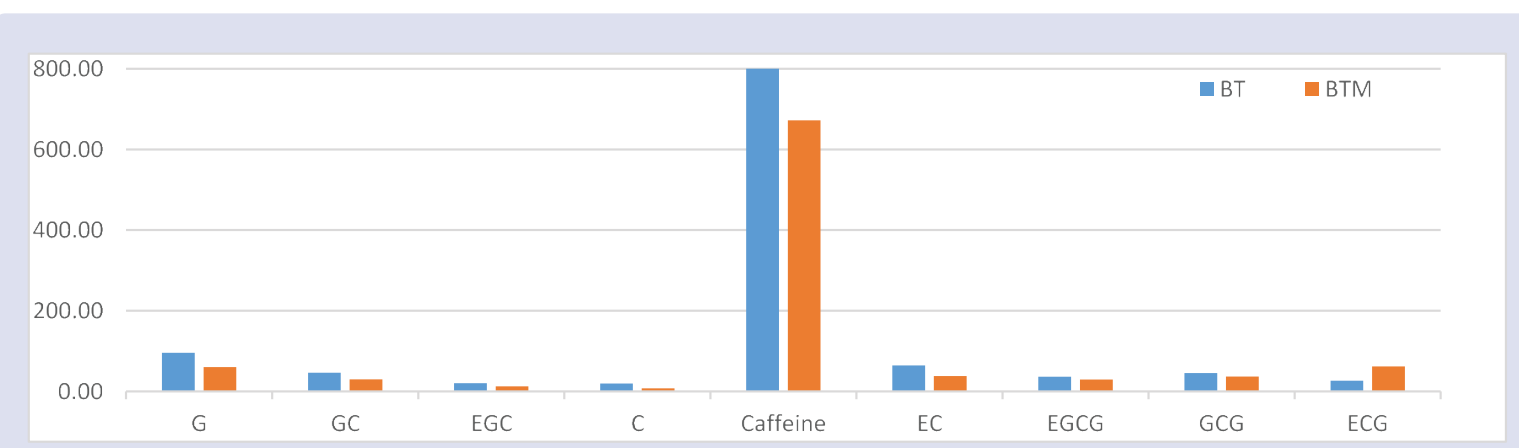

Figure 4: Total identified phenolics in HPLC analysis of both tested samples.

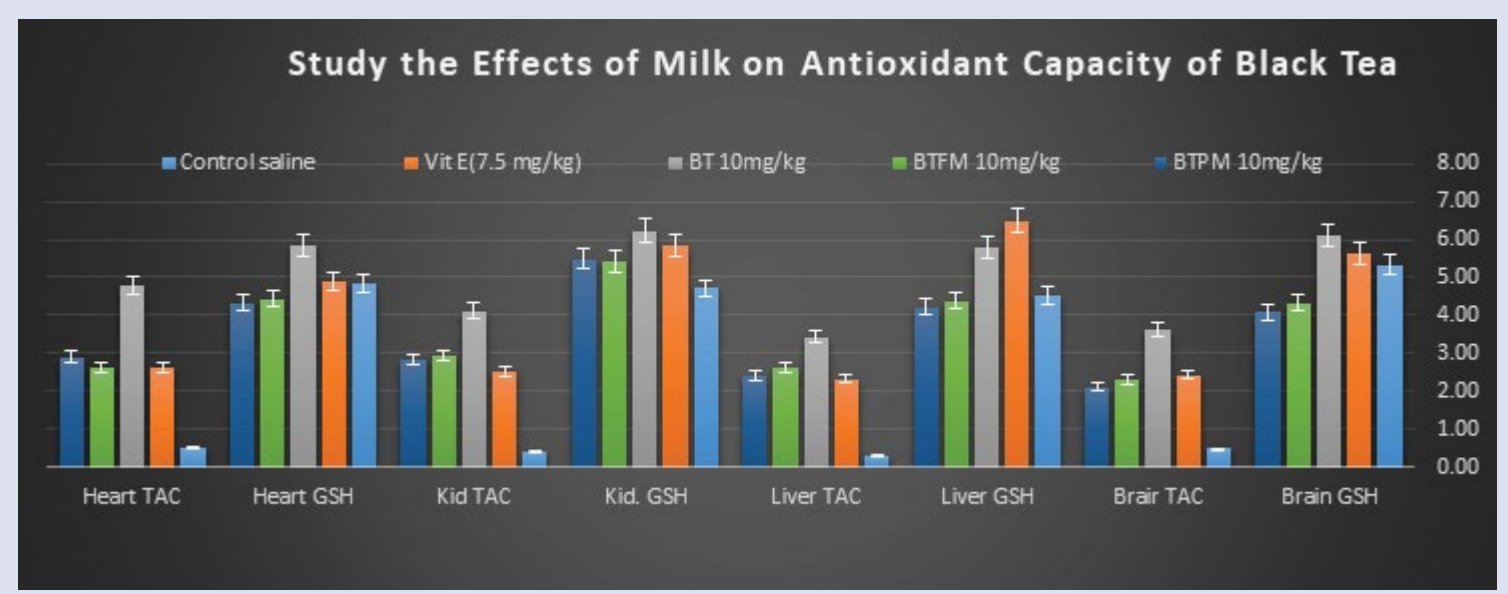

Figure 5: Total antioxidant capacity of tested samples and glutathione reductase level in different rat organs.

Table 4: Total antioxidant capacity of tested samples and glutathione reductase level in different rat organs.

\begin{tabular}{lccccc}
\hline & Control saline & Vit E (7.5 mg/kg) & BT 10 mg/kg & BTFM 10 mg/kg & BTPM 10 mg/kg \\
\hline Brain GSH (mg/dl) & $5.32 \pm 0.18$ & $5.64 \pm 0.12^{\star}$ & $6.12 \pm 0.09^{*}$ & $4.33 \pm 0.07 \bullet$ & $4.09 \pm 0.12 \bullet$ \\
Brain TAC (mM/L) & $0.48 \pm 0.13$ & $2.43 \pm 0.11^{*}$ & $3.62 \pm 0.32^{*}$ & $2.31 \pm 0.1 \bullet$ & $2.1 \pm 0.2 \bullet$ \\
Liver GSH (mg/dl) & $4.53 \pm 0.14$ & $6.49 \pm 0.16^{*}$ & $5.78 \pm 0.11^{*}$ & $4.39 \pm 0.06 \bullet$ & $4.21 \pm 0.13 \bullet$ \\
Liver TAC (mM/L) & $0.31 \pm 0.14$ & $2.32 \pm 0.11^{*}$ & $3.43 \pm 0.27^{*}$ & $2.62 \pm 0.17 \bullet$ & $2.42 \pm 0.13 \bullet$ \\
Kid. GSH (mg/dl) & $4.71 \pm 0.11$ & $5.82 \pm 0.13^{*}$ & $6.24 \pm 0.07^{\star}$ & $5.42 \pm 0.18 \bullet$ & $5.49 \pm 0.16 \bullet$ \\
Kid TAC (mM/L) & $0.42 \pm 0.13$ & $2.51 \pm 0.15^{*}$ & $4.12 \pm 0.31^{*}$ & $2.93 \pm 0.12 \bullet$ & $2.84 \pm 0.14 \bullet$ \\
Heart GSH (mg/dl) & $4.82 \pm 0.12$ & $4.89 \pm 0.13^{*}$ & $5.83 \pm 0.16^{*}$ & $4.43 \pm 0.11 \bullet$ & $4.32 \pm 0.09 \bullet$ \\
Heart TAC (mM/L) & $0.51 \pm 0.12$ & $2.64 \pm 0.14^{*}$ & $4.81 \pm 0.23^{*}$ & $2.63 \pm 0.14 \bullet$ & $2.9 \pm 0.17 \bullet$ \\
\hline
\end{tabular}

* Statistically significant from control group at $P<0.01$

- Statistically significant from tea alone at $P<0.05$ 
binding of polyphenols to milk proteins depends both on the types of both polyphenol and protein. Polyphenols with a galloyl moiety as recorded in HPLC results, have high number of hydroxyl groups and large molecular size so have strong binding affinity to the milk proteins. ${ }^{16}$ Binding of the tea phenolics by the milk proteins diminishes their ability to donate hydrogen atoms ${ }^{17}$ that stabilize the free radicals and hence the deterioration in antioxidant potency. These proteins have mostly high binding affinity towards galloylated molecules that significantly contribute to the antioxidant activity of black tea. Binding of the polyphenolics by milk proteins disguises the active sites such that they do not attain their optimum radical-scavenging capacity. ${ }^{17}$

\section{CONCLUSION}

Percentages of Total polyphenols, and antioxidant activity were significantly $(P<0.05)$ decreased by addition of milk to black tea. Generally, antioxidant activities of black tea infusion approximately 2 fold greater than milk-tea mixture. HPLC analysis confirmed these results as catechins and other polyphenolics were diminished nearly to $1 / 2$ concentration by addition of milk to black tea. The bioactive molecules identified in black teas in this study by HPLC established that black tea possess strong antioxidant power. Addition of extra ingredients, as milk, lowers the antioxidant capacity of tea, which is associated with the positive health effects of the common beverage in Egypt and other countries and therefore tea preparation and consumption habits as milk addition should be modified or reduced so as to maximize potential health benefits of black tea. Further studies are, however, required to assess the isolated molecules and their optimum intake levels, as metabolism of these compounds differs in different body tissues.

\section{DECLARATION OF CONFLICTING INTERESTS}

\section{Ethical approval}

All the pharmacological experiments protocols were conducted according to the ethical norms approved by the National Research Center and followed the recommendations of NRC of Health Guide for care and use of laboratory animals.

\section{Consent to publish}

Not applicable.

\section{Availability of data and materials}

The database used and /or analyzed during the current study are available from the corresponding author on reasonable request.

\section{Competing interests}

The author(s) declared no potential conflicts of interest with respect to the research, authorship, and/or publication of this article. The authors declare no competing interests.

\section{Funding}

The author(s) received no financial support for the research, authorship, and/or publication of this article.

\section{Author contributions}

K. M. Meselhy select the point of research, collect and authenticate plant material, prepared extracts \& fractions, conclude results of antioxidant activity \& and interpret the HPLC analysis \& quantitative determination.

Ghada.A.Abdel-latif, \& A. A. sleem. Carry out the biological activity and measure antioxidant capacity and glutathione reductase level and conclude results of antioxidant activity.

Walaa Ayman, Maram.K.Imam, Kholoud.A.Kassab shared in all practical work as fresh graduates training on research. All authors reviewed the manuscript and concluded the general discussion.

\section{Acknowledgment}

This article was dedicated to the soul of walaa Ayman a senior student has died in a car accident after starting the work in this research.

\section{REFERENCES}

1. Rusak G, Komes D, Likić S, Horžić D, Kovač M. Phenolic content and antioxidative capacity of green and white tea extracts depending on extraction conditions and the solvent used. Food Chemistry. 2008;110(4):852-8.

2. Houghton PJ, Raman A. Laboratory handbook for the fractionation of natural extracts. London: Hall; 1998.

3. Korir MW, Wachira FN, Wanyoko JK, Ngure RM, Khalid R. The fortification of tea with sweeteners and milk and its effect on in vitro antioxidant potential of tea product and glutathione levels in an animal model. Food Chemistry. 2014; 145:145-53

4. Stewart AJ, Mullen W, Crozier A. On-line high-performance liquid chromatography analysis of the antioxidant activity of phenolic compounds in green and black tea. Molecular Nutrition \& Food Research. 2005;49(1):52-60.

5. Peterson J, Dwyer J, Bhagwat S, Haytowitz D, Holden J, Eldridge AL, et al. Major flavonoids in dry tea. Journal of Food Composition and Analysis. 2005;18(6):487-501.

6. Liao S, Kao Y-H, Hiipakka RA. Green tea: Biochemical and biological basis for health benefits. In: Vitam Horm. Volume 62, edn.: Academic Press; 2001:1-94.

7. Mukhtar H, Ahmad N. Tea polyphenols: prevention of cancer and optimizing health. The American Journal of Clinical Nutrition. 2000;71(6):1698S-702S.

8. Arts MJTJ, Haenen GRMM, Wilms LC, Beetstra SAJN, Heijnen CGM, Voss $\mathrm{H}-\mathrm{P}$, Bast A. Interactions between flavonoids and proteins: Effect on the total antioxidant capacity. J Agric Food Chem. 2002;50(5):1184-7.

9. Chan EWC, Lim YY, Chong KL, Tan JBL, Wong SK. Antioxidant properties of tropical and temperate herbal teas. Journal of Food Composition and Analysis. 2010;23(2):185-9

10. Liu X, Zhao M, Wang J, Yang B, Jiang Y. Antioxidant activity of methanolic extract of emblica fruit (Phyllanthus emblica L.) from six regions in China. Journal of Food Composition and Analysis. 2008;21(3):219-28.

11. Attard E. A rapid microtitre plate Folin-Ciocalteu method for the assessment of polyphenols. In: Open Life Sciences.2013;48:48.

12. Herald TJ, Gadgil P, Tilley M. High-throughput micro plate assays for screening flavonoid content and DPPH-scavenging activity in sorghum bran and flour. $J$ Sci Food Agric. 2012;92(11):2326-31.

13. Koracevic D, Koracevic G, Djordjevic V, Andrejevic S, Cosic V. Method for the measurement of antioxidant activity in human fluids. J Clin Pathol. 2001;54(5):356-61.

14. Kaya I, Citil M, Sozmen M, Karapehlivan M, Cigsar G. Investigation of protective effect of I-Carnitine on I-Asparaginase-Induced Acute Pancreatic Injury in Male Balb/c Mice. Dig Dis Sci. 2015;60(5):1290-6.

15. Lorenz M, Jochmann N, von Krosigk A, Martus P, Baumann G, Stangl K, e al. Addition of milk prevents vascular protective effects of tea. Eur Heart J. 2007;28(2):219-23

16. Hasni I, Bourassa P, Hamdani S, Samson G, Carpentier R, Tajmir-Riahi H-A. Interaction of milk $\alpha$ - and $\beta$-caseins with tea polyphenols. Food Chemistry. 2011;126(2):630-9.

17. Dubeau S, Samson G, Tajmir-Riahi H-A. Dual effect of milk on the antioxidant capacity of green, Darjeeling, and English breakfast teas. Food Chemistry. 2010;122(3):539-45. 


\section{GRAPHICAL ABSTRACT}

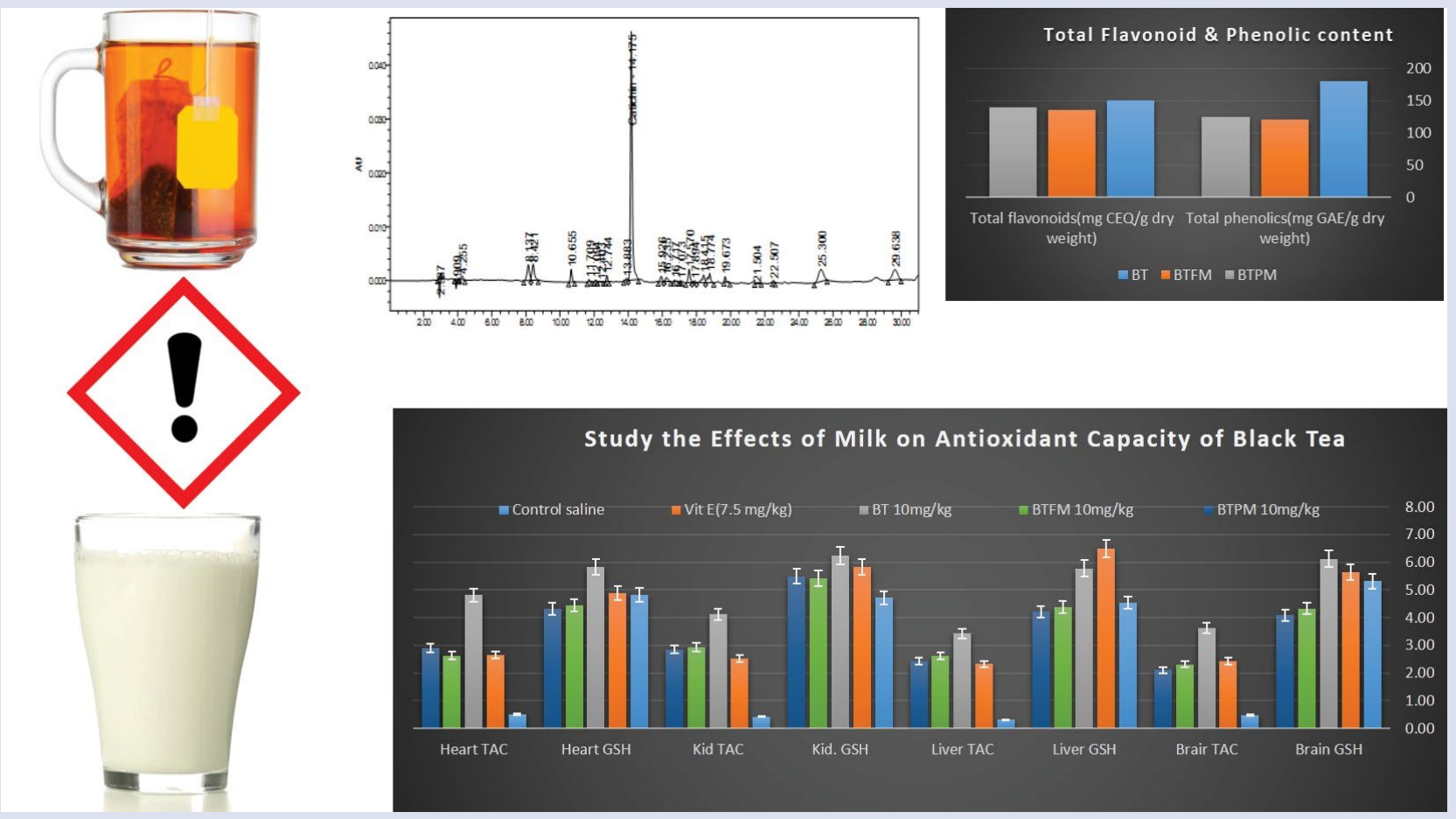

\section{ABOUT AUTHORS}

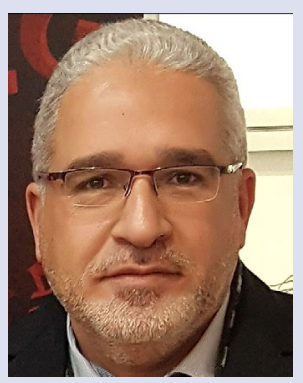

\section{Khaled Meselhy}

Associate professor of Pharmacognosy, Faculty of Pharmacy Cairo University

Awarded the best Master \& Ph.D. awards in pharmacognosy

Received six awards for excellence in performance in the field of educations, quality assurance \& community awareness

Four awards as the best poster and for the innovation in three scientific conferences

Head of scientific committee of $3^{\text {rd }} \& 4^{\text {th }}$ Annual Arab International Pharmacy Conferences

Acting as head of Pharmacognosy department, Faculty of Pharmacy, MIU (2011 -2016)

Assistant vice dean for Community Service and Environment Development Affairs in FOPCU

Published more than 35 Research articles in international journals

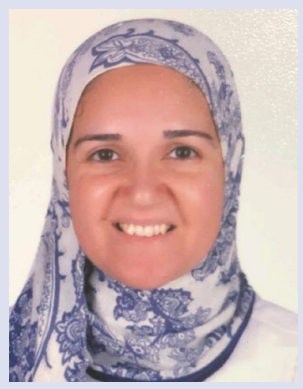

\section{Ghada.A.Abdel-latif}

Assistant professor in pharmacology \& toxicology department, Faculty of Pharmacy, Misr International University

Member of the American Association for cancer research (AACR)

Member of the translational and clinical research unit at the Faculty of Pharmacy, Misr International University

Head of the faculty development and training committee at the quality assurance unit

Chairman of the senior pharmacy students' conference 2019

Published 3 articles in international journals

Participated in 3 international conferences

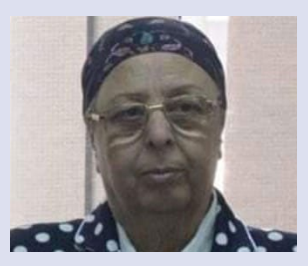

\section{Amany. A. sleem}

Professor in Pharmacology Department, National Research Center, Giza, Egypt

Published more than 100 articles in international journals \& conferences graduated from the faculty of Medicine, Cairo University in 1973, had M.Sc. degree in Pediatrics (1980) Cairo University and Ph.D. degree in childhood studies, Department of Medicine, Institution of Postgraduate studies for childhood (1989) Ain Shams University. She authored or co-authored 265 research papers and supervised 18 M.Sc. and Ph.D. dissertations. She is on the editorial board of the Journal of Egyptian Society of Toxicology. Her research studies focused on natural and synthetic drugs in relation to hepatic disease, cancer and many other health problems. 


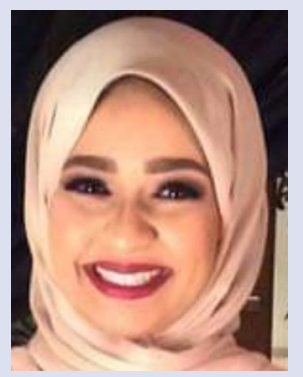

\section{Walaa Ayman}

This article was dedicated to the soul of walaa Ayman a senior student has died in a car accident after starting the idea \& work in this research.

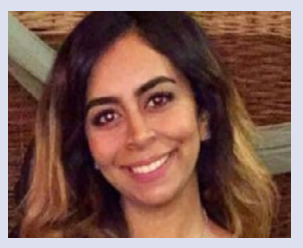

\section{Maram.K.Imam}

Fresh graduates from faculty of pharmacy Misr International University and participated in seniors 19 conference and trained on research methodology in research center at Misr International University.

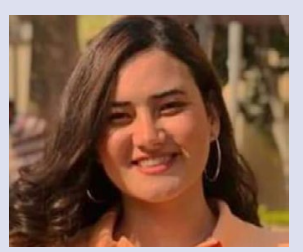

\section{Kholoud.A.Kassab}

Fresh graduates from faculty of pharmacy Misr International University and participated in seniors 19 conference and trained on research methodology in research center at Misr International University.

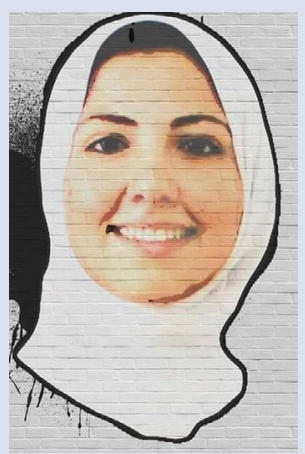

\section{Sherouk Eissa}

Fresh graduates from faculty of pharmacy Misr International University and participated in seniors 19 conference and trained on research methodology in research center at Misr International University.

Cite this article: Meselhy KM, Abdel-latif GA, Sleem AA, Ayman W, Imam MK, Kassab KA, et al. Influence of milk on phenolic composition and antioxidant power of black tea. Pharmacog J. 2019;11(6):1262-8. 